\title{
MIDAS
}

Museus e estudos interdisciplinares

\section{Alejandra Alonso Tak e Ángel Pazos-López (eds.) - Socializing Art Museums: Rethinking the Publics' Experience}

Sofia Carvalho

\section{OpenEdition}

Journals

\section{Edição electrónica}

URL: https://journals.openedition.org/midas/2894

DOI: $10.4000 /$ midas.2894

ISSN: 2182-9543

Editora:

Alice Semedo, Paulo Simões Rodrigues, Pedro Casaleiro, Raquel Henriques da Silva, Ana Carvalho

Refêrencia eletrónica

Sofia Carvalho, «Alejandra Alonso Tak e Ángel Pazos-López (eds.) - Socializing Art Museums: Rethinking the Publics' Experience», MIDAS [Online], 13 | 2021, posto online no dia 15 dezembro 2021, consultado no dia 06 março 2022. URL: http://journals.openedition.org/midas/2894 ; DOI: https:// doi.org/10.4000/midas.2894

Este documento foi criado de forma automática no dia 6 março 2022.

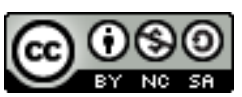

Midas is licensed under a Creative Commons Attribution-NonCommercial-ShareAlike 3.0 International License 


\title{
Alejandra Alonso Tak e Ángel Pazos- López (eds.) - Socializing Art Museums: Rethinking the Publics' Experience
}

\author{
Sofia Carvalho
}

\section{REFERÊNCIA}

Alonso Tak, Alejandra, e Ángel Pazos-López, eds. 2020. Socializing Art Museums: Rethinking the Publics' Experience. Berlin e Boston: De Gruyter. 400 páginas, ISBN 978-3-11-064632-0.

1 A discussão sobre o papel social dos museus tem-se vindo a intensificar, progressiva e exponencialmente, desde aquele que representa oficialmente o início desta reflexão de forma pública e internacional: a Mesa-Redonda de Santiago do Chile de 1972, organizada pela Organização das Nações Unidas para a Educação, Ciência e Cultura (UNESCO) e pelo Conselho Internacional de Museus (ICOM) (Junior, Trampe e Santos 2012).

2 Desde então, o debate sobre a relação que o museu deve - ou não - estabelecer com os desafios e as especificidades da sociedade contemporânea tem vindo a ser explorado por diferentes vias, nomeadamente, através de encontros, publicações e projetos que visam a partilha de saberes e de práticas entre todos aqueles interessados em museus $\mathrm{e}$ na possibilidade de acionar o poder destas instituições como agentes de transformação social. Tratando-se de um debate que visa o diálogo entre museu/sociedade, ele transgride as paredes do museu, envolvendo não só profissionais de museu, mas também artistas, ativistas, sociólogos, antropólogos, entre outros.

3 Segundo esta abordagem social, multidisciplinar por natureza, centrada no envolvimento recíproco entre o museu e as comunidades que serve, verifica-se 
especialmente pertinente um olhar atento aos públicos de museu, nomeadamente no que diz respeito à sua diversidade, representatividade e acessibilidade em espaços museológicos. É neste âmbito que surge o livro em recensão, Socializing Art Museums: Rethinking the Publics' Experience.

Este é um livro que propõe explorar e ampliar a aplicação de uma abordagem social aos museus, em particular, no que diz respeito a museus e galerias de arte. Assume como objetivo proporcionar uma visão abrangente, internacional e multidisciplinar relativa às tendências e práticas museológicas atuais comprometidas com a acessibilidade em museus e em tornar os museus mais inclusivos.

Os editores, Alejandra Alonso Tak (gestora de projeto no Ministério da Cultura de França) e Ángel Pazos-López (investigador na Universidade Complutense de Madrid), colaboram ativamente com o Consórcio MUSACCES. Foi no âmbito das atividades deste consórcio científico que o mote para a criação deste livro foi lançado. A partir da conferência internacional The Limits of Art in the Museum (ocorrida entre os dias 29 e 30 de novembro de 2017) coordenada, inclusive, por Alejandra Alonso Tak, foram discutidas algumas das temáticas que se encontram plasmadas neste livro.

Estruturado em cinco secções que se desdobram em 19 capítulos, este livro conta com o contributo de um total de 28 autores da Alemanha, Bélgica, Canadá, Espanha, Escócia, França, Suíça e Portugal. Sendo que a esmagadora maioria é proveniente do universo académico, com especial destaque para a representação de investigadores de várias universidades espanholas.

7 Na primeira secção, «Museums and Audiences in the 21st Century», é explorado o papel social dos museus na contemporaneidade. Hans-Martin Hinz, antigo presidente do ICOM, reflete sobre o modo como a (in)dependência científica dos museus condiciona a resposta destas instituições às exigências da sociedade de hoje. Eloísa Pérez Santos, coordenadora do Laboratorio Permanente de Público de Museos, apresenta o modelo adotado pelo Governo de Espanha na realização de estudos de públicos. Por sua vez, os investigadores da Universidade de Deusto, Iñigo Ayala, Macarena Cuenca-Amigo e Jaime Cuenca, analisam a perceção dos públicos face às transformações que têm vindo a decorrer nos museus em termos de acessibilidade e estímulo à participação. Álvaro Notario Sánchez, da Universidade de Castilla-La Mancha, explora o modo como as tecnologias da informação e comunicação podem servir de veículo à concretização da missão do museu. Por fim, Luis Walias Rivera, investigador da Universidade de Cantabria, apresenta o Centro Botín de Satander como caso de estudo sobre as potencialidades da aplicação de uma estratégia de marketing centrada na empatia em contexto museológico.

8 A segunda secção do livro, «Education Strategies in Museums», debruça-se sobre educação e pedagogia em museus. Alice Semedo, professora na Universidade do Porto, reflete sobre a necessidade de o museu estar comprometido com um pensamento ético que o leva a atuar, reflexivamente, nos processos de escrutínio e de ressignificação do conhecimento que ele próprio (re)produz. Por seu turno, Nicole Gesché-Koning, professora honorária da Academia Real de Belas Artes de Bruxelas, analisa um conjunto de práticas engajadas com a acessibilidade e inclusão social em museus, conduzidas por instituições culturais da Bélgica. Esta secção finaliza com um capítulo de Stéphanie Masuy, responsável pelos Serviços de Educação no Museu de Ixelles, que apresenta em detalhe o projeto Musée Comme Chez Soi, responsável por, através de uma atividade "fora 
de portas" durante um período de encerramento do museu, continuar a expor as coleções e reforçar a interação com os públicos.

9 Segue-se a terceira secção, «Museums as Forums for Citizenship», que analisa o modo como os museus podem ser instrumentais para o desenvolvimento de pensamento crítico e de contribuírem para a transformação social. Martyna Ewa Majewska, da Universidade de St. Andrews (Escócia), analisa a influência que manifestações ativistas direcionadas a museus de arte em Nova Iorque tiveram na alteração do comportamento desses mesmos museus. Seguem-se três capítulos, todos eles da autoria de investigadoras da Universidade Complutense de Madrid. Marián López Fernández Cao propõe que os museus, enquanto espaços transicionais, podem contribuir para melhor lidar e compreender sentimentos como trauma, destruição e culpa, quer ao nível individual, quer comunitário. Por sua vez, Carolina Peral Jiménez aborda os impactos da representação de violência contra mulheres em museus, apresentando um projeto pioneiro, responsável por acionar mecanismos de resistência face ao androcentrismo dos museus espanhóis. E por último, Tamara Bueno Doral, Irene González Hernando e Rosaura Navajas Seco analisam a aplicação da abordagem da Responsible Research and Inovation (RRI) como veículo para a integração social em museus.

10 Segue-se a quarta secção, «Accessibility in Museums», que se debruça sobre públicos com diversidade funcional nos domínios cognitivo e motor. Inicia com um capítulo da autoria dos editores deste livro, Ángel Pazos-López e Alejandra Alonso Tak, no qual são sintetizadas as ações conduzidas pelo Consórcio MUSACCES, entre 2016 e 2019, no que diz respeito à acessibilidade universal em museus e em contexto académico. Por sua vez, Marta Pucciarelli, Luca Morici e Jean-Pierre Candeloro, investigadores da Escola Universitária Profissional da Suíça Italiana, apresentam um projeto desenvolvido no Museu Vincenzo Vela para a acessibilidade de pessoas com deficiência visual às coleções através de descrições narrativas. A secção é finalizada pelos professores da Universidade de Salamanca, María Victoria Martín Cilleros e Miguel Elías Sánchez Sánchez, que apresentam uma atividade conduzida na Fundação Venancio Blanco com jovens com síndrome de Asperger e autismo de alta funcionalidade, com o objetivo de contribuir para participação plena destes jovens na comunidade.

11 A quinta e última secção do livro, «Rethinking Spaces in Museums», é dedicada à reflexão sobre o modo como o espaço expositivo influencia a experiência dos públicos. Alexandra Irimia, da Universidade de Ontário Ocidental, abre esta secção com uma reflexão sobre como desde o século XX artistas têm recorrido ao "esvaziamento" do espaço expositivo como veículo a diferentes formas de experienciar o museu. Por sua vez, David Gallardo López, Silbia Idoate Pérez e Patricia Navarro Cantón, associados ao LIME - Laboratorio de Investigación y Experimentación Museográfica, apresentam a Vitrina 3.0 que possui um vidro inteligente capaz de potenciar a comunicação dos objetos de arte e a interação com estes por via das redes sociais. O livro termina com um capítulo da autoria de Juan Carlos Rico Nieto, no qual o ex-diretor do já aqui referido LIME faz um relato honesto sobre aquela que foi a metodologia, os sucessos e os fracassos que o projeto enfrentou entre 2016 e 2017.

12 O livro apresenta um número significativo de perspetivas, práticas e diferentes aproximações à temática da acessibilidade em museus, muitas delas inovadoras e experimentais. Esta publicação revela, assim, a complexidade do tema nas suas múltiplas ramificações, possibilitando ao leitor uma análise das várias facetas sobre as quais atualmente o tema é trabalhado; aspeto que corresponde, inclusive, a um dos 
objetivos enunciados pelos editores. Contudo, os autores dos capítulos representam um conjunto de países circunscritos, na sua grande maioria, ao contexto europeu, sendo todos eles associados ao norte global. Para um livro que procura representar uma visão ampla e internacional, seria interessante se tivesse contemplado também práticas e reflexões oriundas de outras latitudes e contextos.

Importa destacar a relevância e atualidade do tema, sendo a relação museu/sociedade um tema enquadrado no cerne das principais problemáticas debatidas pelos especialistas na área do património e da museologia. Serve de exemplo o modo como esta temática se encontra plasmada nas importantes e recentes conferências debruçadas sobre o tema "Museus e Responsabilidade Social", ocorridas entre 2020 e 2021, no âmbito do Trio de Presidências do Conselho da União Europeia (Alemanha, Portugal e Eslovénia) (NEMO 2020; DGPC 2021; Slovenian Museum Association 2021).

Dada a relevância do tema, bem como da inovação e importância que pauta as reflexões e iniciativas que constam neste livro, Socializing Art Museums estabelece-se como uma bibliografia de referência. Não só para a identificação das atuais tendências no que diz respeito à acessibilidade em museus, mas também para desvendar potenciais caminhos para tornar os museus mais engajados, permeáveis e responsivos aos desafios da sociedade contemporânea. Estes motivos espelham o modo como este livro está comprometido com um debate que é atual, relevante e urgente.

\section{BIBLIOGRAFIA}

DGPC. 2021. "Museus e Responsabilidade Social: Participação, Redes e Parcerias.” DGPC (DireçãoGeral do Património Cultural). http://conferencemuseumsandsocialresponsibility.dgpc.pt/ Junior, José Nascimento, Alan Trampe, e Paula Assunção Santos, orgs. 2012. Mesa Redonda de Santigo de Chile 1972, vol. 1: Mesa Redonda sobre la Importancia y el Desarrollo de los Museos en em Mundo Contemporáneo. Brasília: Instituto Brasileiro de Museus.

NEMO. 2020. "Museums and Social Responsibility: Values Revisited." NEMO (Network of European Museum Organisations). https://www.ne-mo.org/about-us/eu-presidency-museum-conference Slovenian Museum Association. 2021. "Museums and Social Responsibility - What Comes Next?" http://museums.si/en-us/Home/Sms-Conference

\section{AUTORES}

\section{SOFIA CARVALHO}

CITCEM - Centro de Investigação Transdisciplinar «Cultura, Espaço e Memória», Universidade do Porto, Portugal, sofia.carvalho.ac@gmail.com 